University of Nebraska - Lincoln

DigitalCommons@University of Nebraska - Lincoln

USDA National Wildlife Research Center - Staff Publications
U.S. Department of Agriculture: Animal and Plant Health Inspection Service

2019

\title{
Allowable Take of Black Vultures in the Eastern United States
}

Guthrie Zimmerman

U.S. Fish and Wildlife Service, guthrie_zimmerman@fws.gov

Brian A. Millsap

U.S. Fish and Wildlife Service, brian_a_millsap@fws.gov

Michael L. Avery

John R. Sauer

USGS Patuxent Wildlife Research Center

Michael C. Runge

USGS Patuxent Wildlife Research Center

See next page for additional authors

Follow this and additional works at: https://digitalcommons.unl.edu/icwdm_usdanwrc

Part of the Life Sciences Commons

Zimmerman, Guthrie; Millsap, Brian A.; Avery, Michael L.; Sauer, John R.; Runge, Michael C.; and Richkus, Kenneth D., "Allowable Take of Black Vultures in the Eastern United States" (2019). USDA National Wildlife Research Center - Staff Publications. 2206.

https://digitalcommons.unl.edu/icwdm_usdanwrc/2206

This Article is brought to you for free and open access by the U.S. Department of Agriculture: Animal and Plant Health Inspection Service at DigitalCommons@University of Nebraska - Lincoln. It has been accepted for inclusion in USDA National Wildlife Research Center - Staff Publications by an authorized administrator of DigitalCommons@University of Nebraska - Lincoln. 


\section{Authors}

Guthrie Zimmerman, Brian A. Millsap, Michael L. Avery, John R. Sauer, Michael C. Runge, and Kenneth D. Richkus 


\title{
Allowable Take of Black Vultures in the Eastern United States
}

\author{
GUTHRIE S. ZIMMERMAN, ${ }^{1}$ U.S. Fish and Wildlife Service, Division of Migratory Bird Management, 3020 State University Drive East, \\ Modoc Hall, Suite 2007, Sacramento, CA 95819, USA \\ BRIAN A. MILLSAP, U.S. Fish and Wildlife Service, Division of Migratory Bird Management, 2105 Osuna NE, Albuquerque, NM 87113, USA \\ MICHAEL L. AVERY, ${ }^{2}$ U.S. Department of Agriculture, Animal and Plant Health Inspection Service, Wildife Services, National Wildlife Research \\ Center, Florida Field Station, 2820 E. University Avenue, Gainesville, FL 32641, USA \\ JOHN R. SAUER, U.S. Geological Survey, Patuxent Wildife Research Center, 12100 Beech Forest Road, Laurel, MD 20708, USA \\ MICHAEL C. RUNGE, U.S. Geological Survey, Patuxent Wildlife Research Center, 12100 Beech Forest Road, Laurel, MD 20708, USA \\ KENNETH D. RICHKUS, U.S. Fish and Wildlife Service, Division of Migratory Bird Management, 5275 Leesburg Pike, Falls Church, VA 22041, \\ $U S A$
}

\begin{abstract}
Black vultures (Coragyps atratus) have been increasing in density and expanding their range in the eastern United States since at least the 1960s. In many areas, their densities have increased to the level where they are causing damage to property and livestock and the number of requests for allowable take permits has increased throughout these areas. The United States Fish and Wildlife Service (USFWS) requires updated information to help inform the number of take permits that could reduce conflicts while meeting obligations under the Migratory Bird Treaty Act. We expanded analyses used to estimate allowable take in Virginia to cover the range of black vultures in the eastern United States. We used the prescribed take level approach, which integrates demographic rates, population size estimates, and management objectives into an estimate of allowable take. We provide estimates of allowable take at 4 different scales: individual states, Bird Conservation Regions, USFWS administrative regions, and flyways. Our updated population time series provides evidence of rapidly increasing black vulture populations in many regions of the eastern United States, with an overall population estimate of approximately 4.26 million in 2015 in the Atlantic and Mississippi Flyways. Estimated allowable take ranged from a few hundred individuals per year in states at the northern end of the species range to approximately 287,000/year over the entire eastern United States. The USFWS has no legal mandate regarding the spatial scale at which take should be managed and we found little biological evidence of subpopulation structure for black vultures in the eastern United States. We suggest that allowable take for the species be implemented at a scale that meets stakeholder objectives (e.g., reducing conflict, and ensuring that black vultures are not extirpated from local areas) and is efficient for administrative and monitoring purposes. Published 2018. This article is a U.S. Government work and is in the public domain in the USA.
\end{abstract}

KEY WORDS allowable take, black vulture, Breeding Bird Survey, Coragyps atratus, hierarchical model, populations, trend.

The United States Fish and Wildlife Service (USFWS) issues permits for the lawful take, live and dead, of migratory birds under various laws and treaties, including the Migratory Bird Treaty Act (16 USC $\S \S 703-712)$ and the Bald and Golden Eagle Protection Act (16 USC §§668$668 \mathrm{~d})$. These permits are used for a variety of purposes and are intended to balance human use and conservation of migratory birds. Specifically, permits allow individuals to engage in activities that would otherwise be illegal for the purposes of reducing human-wildlife conflicts, providing

Received: 27 June 2018; Accepted: 8 October 2018

${ }^{1}$ E-mail: guthrie_zimmerman@fws.gov

${ }^{2}$ Retired. recreational opportunity (e.g., sport hunting, falconry), providing food (e.g., subsistence harvest), and allowing religious and cultural traditions (e.g., feathers and other bird parts for tribal activities).

Vultures are highly effective scavengers, and ecologically and economically important components of ecosystems worldwide (Ogada et al. 2012). In the United States, black vultures (Coragyps atratus) historically were distributed primarily in the southeastern states, but populations have been rapidly increasing and expanding north and west over the past several decades (Avery 2004). Black vultures congregate in large communal roosts and primarily forage as scavengers. Unlike sympatric turkey vultures (Cathartes aura), however, they do prey on live animals (Buckley 1999). Consequently, black vultures frequently come into conflict with humans by causing structural damage (e.g., ripping roof 
shingles and membranes, fouling structures with feces, tearing upholstery), depredating livestock, and colliding with aircraft (Lowney 1999, Avery and Cummings 2004, Avery and Lowney 2016). A variety of techniques are used to deter black vultures, including exclusion, harassment with pyrotechnics and lasers, translocation, guard dogs, and other methods (Avery and Lowney 2016). When these non-lethal methods do not work, problem individuals are targeted for lethal take.

The rapidly growing population of black vultures in the eastern United States is leading to more frequent interactions and reports of conflict with humans (Lowney 1999, Avery and Cummings 2004), which has prompted requests for the USFWS to authorize lethal control of black vultures in areas where documented damage is occurring and non-lethal control measures do not work. The USFWS has committed to using science-based approaches to guide take of migratory birds (https:/www.landcan.org/pdfs/finalmbstratplan.pdf, accessed 24 Aug 2018) and is assessing alternatives for a take-permitting program for this species. Although there is no explicit expectation that an informed decision-making framework be used to inform black vulture take in the United States, our analysis provides a flexible approach that can be applied to an informed decision-making framework given clearly stated objectives, alternatives, and risk. We conducted our assessment following the USFWS's operating policy to manage take in a sustainable manner.

Our objective was to evaluate biologically sustainable take levels for black vultures in the eastern United States. Specifically, we aimed to update the prescribed take levels for Virginia specified in Runge et al. (2009) with current North American Breeding Bird Survey (BBS) data (Sauer et al. 2017) for that state, and expand the assessment to include other states where black vultures were detected during BBS surveys in the Atlantic and Mississippi Flyways. We also explored the possibility of larger scale management areas (e.g., Bird Conservation Regions [BCRs], USFWS regions, flyways).

\section{STUDY AREA}

Black vultures in the United States historically were limited to the Southeast. However, their range has been expanding north and west for the past several decades (Avery 2004, Sauer et al. 2017). We limited our modeling of allowable take to areas where black vulture populations were large enough to be estimated using BBS data within states and BCRs in the eastern half of the United States from 1966 to 2015. We observed black vultures on BBS routes in states from Florida north to New York along the Atlantic coast, and west to Illinois, Missouri, Arkansas, and Louisiana (Fig. 1). Within these states, most vultures were observed in the Central Hardwoods, West Gulf Coastal Plain/Ouachitas, Mississippi Alluvial Valley, Southeastern Coastal Plain, Piedmont, New England/Mid-Atlantic Coast, Peninsular Florida, and Gulf Coastal Prairie BCRs. Detailed descriptions including weather, climate, topography, major plant communities, and common wildlife for each of these BCRs is available at the North American Bird Conservation Initiative web site (http://nabci-us.org/resources/bird-conservation-regionsmap/, accessed 29 Oct 2018). Although black vultures occur outside of this range in the eastern United States, not enough were observed along BBS routes elsewhere to derive population size estimates. Most nuisance complaints about black vultures occur within this range, particularly in areas where vultures have recently expanded. Nonetheless, the USFWS receives complaints from outside of this range, indicating that the population continues to expand. The framework we present can be expanded when data become available to estimate population size in newly colonized portions of the black vulture range.

\section{METHODS}

\section{Prescribed Take Level}

The prescribed take level (PTL) framework employed by Runge et al. (2009) uses demographic rates (e.g., recruitment, survival) to estimate a maximum annual growth rate $\left(r_{\max }\right)$. Assuming density-dependent growth under a discrete logistic model, $r_{\max } / 2$ provides an estimate of a biologically sustainable take rate (Runge et al. 2004, 2009; Johnson et al. 2012). The estimate of take rate, multiplied by a population size estimate $(N)$ and a management objective $\left(F_{o}\right)$ estimates annual allowable take (i.e., the PTL) in numbers of birds (Runge et al. 2009, Johnson et al. 2012):

$$
P T L=F_{0} \times \frac{r_{\max }}{2} \times N
$$

The management objective expresses the long-term population goal of the manager relative to carrying capacity and can range between 0 and 2 . An objective of 1 represents maximum sustained yield and is expected to keep the population at about 0.5 of carrying capacity. Values near 0 allow very little take and should allow the population to equilibrate near carrying capacity over the long term, whereas values near 2 would result in relatively large levels of take and hold the population to a small proportion of carrying capacity. From an operational perspective, $F_{o}<1$ is considered for species where managers are concerned about populations being too small and $F_{o}>1$ is considered for perceived over-abundant or nuisance species (Runge et al. 2009). Each of these components can be modeled as time-specific if time series of data are available or objectives change.

Our analysis of allowable take differed from Runge et al. (2009) in allowing the form of density dependence in the underlying discrete logistic model to be non-linear. Johnson et al. (2012) and Williams (2013) reported that the form of density dependence can influence optimal take. The thetalogistic model incorporates nonlinear density dependence with a parameter $\theta$ (Gilpin and Ayala 1973):

$$
N_{t+1}=N_{t}+r_{\max } \times N_{t} \times\left\lceil 1-\left(\frac{N_{t}}{K}\right)^{\theta}\right\rceil
$$

In this model, $\theta=1$ represents linear density dependence, $\theta$ $>1$ indicates density dependence is strongest at population levels close to carrying capacity $(K)$, and $\theta<1$ indicates that density dependence is strongest at population levels much 


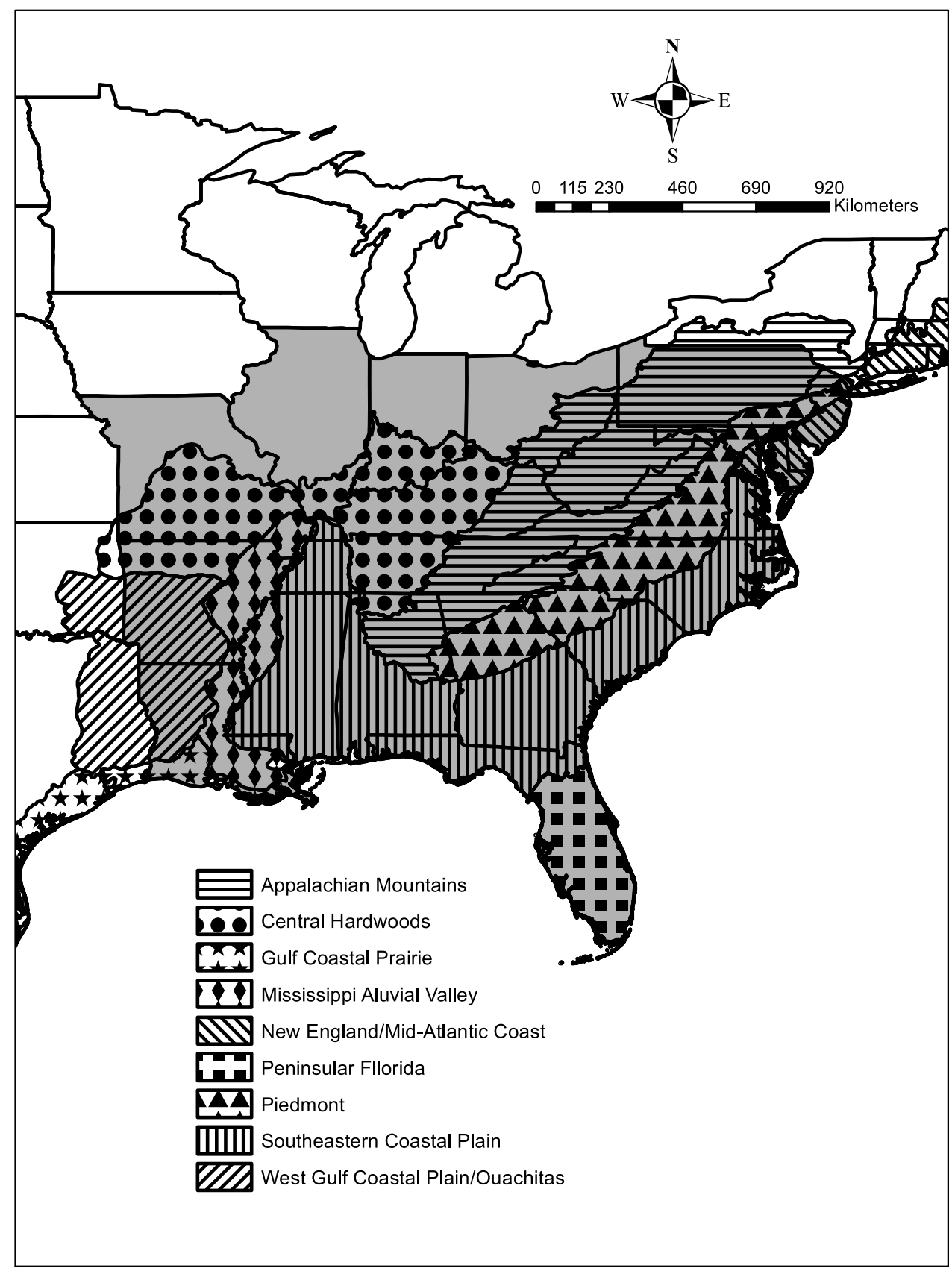

Figure 1. States (shaded gray) and Bird Conservation Regions for which we estimated population size and allowable take for black vultures in the eastern United States, 2015.

smaller than carrying capacity (Sæther et al. 2002). The parameters of the theta-logistic model are difficult to estimate with field data (Clark et al. 2010) and there has been debate about patterns in the form of growth rate and life-history traits of animal populations (Sibly et al. 2005, Clark et al. 2010). Johnson et al. (2012) derived PTL for the $\theta$-logistic model as:

$$
P T L=F_{\circ} \times \frac{r_{\max } \times \theta}{(\theta+1)} \times N
$$

and conducted simulations to assess how different forms of density dependence could influence PTL of songbirds. They assumed a negative relationship between $\theta$ and $r_{\max }$ (Sæther and Engen 2002) and reported that allowable take for songbirds was lower than what it would have been assuming linear density dependence. We calculated $\theta$ as a function of $r_{\max }$ using the regression model fit by Johnson et al. (2012:1119):

$$
\log (\theta)=1.129-1.824 \times r_{\max }+e,
$$

where $e$ approximated $\operatorname{Normal}\left(0, \sigma^{2}\right)$ and $\sigma^{2}=0.942$. We incorporated uncertainty in the relationship between $\theta$ and $r_{\max }$ for black vultures by assuming fixed parameter values (i.e., 1.129 and 1.824) and sampling from the error distribution for $\sigma^{2}$ during simulations. 


\section{Estimating $r_{\text {max }}$}

We defined $r_{\max }$ as the expected growth rate under average environmental conditions, in the absence of take and Allee effects, and when density dependence is not limiting survival or recruitment (Runge et al. 2004). One critical consideration for $r_{\max }$ is that it depends on environmental conditions; if the environment changes, $r_{\max }$ for a species will change (Caughley 1977, Sibly and Hone 2003). Therefore, as Runge et al. (2004) point out, the estimate of $r_{\max }$ should not represent environmental conditions that could lead to unrealistic values for the modeled species. For example, if an environmental shift occurred that reduced available food for a population, values of $r_{\max }$ representing the prior environment could lead to take levels that were unsustainable. A second important consideration is that the definition of $r_{\max }$ is different than the observed growth rate because $r_{\text {max }}$ is defined under conditions that are rarely met in field settings (e.g., very low population densities, absence of take). Environmental and biological conditions are rarely conducive for estimating $r_{\max }$ based on population surveys, and even for species like black vultures that are increasing rapidly, it is difficult to ascertain whether observed growth is fully density independent and thus indicative of $r_{\text {max }}$. Applications of the PTL framework avoid this uncertainty by using upper confidence bounds of estimated $r_{\max }$ from demographic modeling of field data (Runge et al. 2009) or allometric relationships estimated from captive-held animals (Johnson et al. 2012).

As in Runge et al. (2009), we used Slade's formula (Slade et al. 1998) to estimate $r_{\max }$ from information describing age at first breeding, age of senescence, adult survival, fledglings per breeding adult, and survival from fledging to breeding age. We estimated fledglings per adult as the product of probability of a breeding-age individual breeding in a given year and fledglings per breeding adult. We estimated survival to age of first breeding as the product of first-year survival and subadult survival raised to the power of age at first breeding minus 1 (Runge et al. 2009). We used estimates of the demographic rates and uncertainty used by Runge et al. (2009). We did not find any updated data in the literature since Runge et al. (2009), and raptor biologists who had been authorized for a black vulture banding permit by the Bird Banding Laboratory could not provide additional information that could be used to update the demographic information provided by Runge et al. (2009).

\section{Estimating $N$}

We used the Runge et al. (2009) approach for estimating $N$ as model-based adjustments of BBS indices estimated at the scale of BCRs within states (Sauer et al. 2013). Volunteers conduct the BBS at survey points along roadside routes from April through June, between 30 minutes before sunrise and about 4 hours after sunrise (Robbins et al. 1986). Routes are $39.4 \mathrm{~km}$ long and survey points occur at $0.8-\mathrm{km}$ intervals. Observers are instructed to count every bird heard or seen within $400 \mathrm{~m}$ for a 3-minute period at each point.

Population change from BBS data is computed using a loglinear hierarchical model, implemented within strata formed by the intersection of states and BCRs, which estimates trend and year effects and includes controls for observer and route effects (Sauer et al.2013). We limited the analysis to strata (i.e., BCR-state combinations) that had $\geq 4 \mathrm{BBS}$ routes where black vultures were observed to improve the performance of the hierarchical model. Annual indices are computed as derived statistics in a Bayesian analysis. The hierarchical model allows for incorporation of adjustments to the annual BBS indices that convert them from indices to estimated population size (Runge et al. 2009). Following Runge et al. (2009), we converted the BBS indices to population estimates by adjusting indices for detection rates, correcting indices for area sampled along routes (assuming a detection radius of $400 \mathrm{~m}$ around each point), adjusting the index by the proportion of birds observed flying during BBS surveys (Runge et al. 2009:560) to derive a population estimate of flying vultures, and correcting the population estimate of flying vultures for availability to be detected during surveys (Avery et al. 2011).

Runge et al. (2009) reported no evidence to indicate that detection rates on- versus off-road differed, so we used the same adjustments for detection, proportion of birds observed flying, and availability computed by Runge et al. (2009) for all routes. In practice, stratum-level estimates were thus adjusted population sizes per route multiplied by the number of routeareas within a stratum. We aggregated the stratum-level estimates of population size by summation to 34 spatial units: 20 states for which we had enough black vulture observations to run the BBS analysis (Fig. 1), 9 BCRs (Fig. 1), 3 USFWS regions (Regions 3, 4, and 5; see map at https://www.fws.gov/ endangered/regions/index.html, accessed 15 Aug 2018), and 2 flyways (the Atlantic and Mississippi Flyways; see map at https://www.fws.gov/birds/management/flyways.php, accessed 15 Aug 2018).

\section{Simulations}

We incorporated uncertainty in take levels through Monte Carlo simulations where values of demographic rates, $\theta$, and population size were sampled from the statistical distributions described by Runge et al. (2009). We ran 100,000 replicates, sampled demographic rates from the statistical distributions for each parameter, and estimated $r_{\max }$ and $\theta$ for each replicate. For each spatial unit, we sampled a population size from the median and standard deviation of the population size estimates generated from the BBS data as described in the previous section. We transformed the median and standard deviation to the log normal scale and sampled population size estimates from the log normal distribution to eliminate the possibility of sampling values $<0$. For this assessment, we specified a management objective of maximum sustained yield (i.e., $\left.F_{o}=1\right)$. Therefore, we calculated an allowable take value for each iteration by multiplying the sampled $N$ by the calculated take rate estimated from the theta-logistic model (i.e., $\left.\left[\theta \times r_{\text {max }}\right] /[\theta+1]\right)$ for that iteration. We summarize our results as medians and $95 \%$ quantiles of the distributions of take levels from 100,000 iterations of the Monte Carlo simulations.

\section{RESULTS}

Our estimate of maximum intrinsic growth rate $\left(r_{\max }=0.11\right.$, $95 \% \mathrm{CI}=0.02-0.19)$ was similar to Runge et al. (2009), 
which was expected given we used the same demographic parameters. However, our take rate $\left(b_{\max }=0.07,95 \%\right.$ $\mathrm{CI}=0.01-0.15)$ was slightly higher than Runge et al. (2009, assumed to be $0.5 \times r_{\max }$ ) because we accounted for nonlinearity in density dependence by using a theta-logistic model in which our estimate of $\theta$ was $>1$ with high uncertainty $(\theta=2.56,95 \% \mathrm{CI}=0.37-17.44)$. The number of survey routes on which black vultures were encountered between 1966 and 2015 was 1,016. Population estimates based on BBS data were highly uncertain (Figs. 2-4) with the lowest mean coefficients of variation at the larger scales $(22 \%$ for USFWS Region 4, 26\% for the Mississippi Flyway, 28\% for the Atlantic Flyway). Areas with the fewest counts of vultures had coefficients of variation that were particularly high (Missouri $\mathrm{CV}=226 \%$, Indiana $\mathrm{CV}=161 \%$, New Jersey CV $=119 \%$, and Gulf Coast Prairie BCR CV $=103 \%)$. Almost all regions indicated increasing trends of black vultures, with some areas having increases indicating exponential growth (Figs. 2-4). Flyway-wide, we estimated approximately 2.51 million black vultures in the Atlantic Flyway and 1.75 million in the Mississippi Flyway in 2015. At the largest scale, estimated allowable take was approximately 169,000 in the Atlantic Flyway and 118,000 in the Mississippi Flyway. At the state-scale, allowable take varied widely ranging from 295 birds in Ohio to approximately 75,000 in Florida, reflecting the distribution of abundance based on the BBS (Table 1).

\section{DISCUSSION}

Wildlife managers consider lethal control a last resort for dealing with nuisance wildlife, for use only after non-lethal methods have been exhausted. The increasing availability of omnibus species population monitoring programs such as the BBS, combined with hierarchical models that permit direct incorporation of adjustments for detection components in sampling, make the PTL framework an appealing approach for estimating allowable take for wildlife. Our population models indicated that black vulture population size is approximately 4.26 million birds and is increasing rapidly throughout the Atlantic and Mississippi Flyways. Incorporating these large population size estimates with demographic data, our PTL framework indicated that, sustainably, approximately 287,000 black vultures could be removed from the 2 flyways annually. Although our results indicate this level of take may be biologically sustainable, previous studies have shown that, alone, broad-scale lethal removal efforts are often futile for managing nuisance species in agricultural landscapes (Linz et al. 2015). This may be especially true for black vultures, because the population is large, mobile, social, and opportunistic. Locally, however, managers may reduce conflict through selective removal combined with aggressive harassment (including use of guard dogs), dispersing individuals from night roosts, and husbandry options to protect birthing female and newborn livestock from predatory vultures (Humphrey et al. 2004, Milleson et al. 2006, Avery and Lowney 2016). Our estimate of sustainable take provides an upper limit on the lethal removal to be undertaken in conjunction with other measures.

\section{Management Objectives and Risk}

Important policy decisions to be considered when implementing the results of the PTL for informing allowable take include the choice of the management objective (i.e., value of $\left.F_{o}\right)$, the risk tolerance embedded in the choice of population size $(N)$ from its uncertainty distribution, and the risk tolerance embedded in the choice of $r_{\max }$ from its uncertainty distribution (Runge and Sauer 2017). We assumed a management objective of maximum sustained yield $\left(F_{o}=1\right)$, which may or may not represent regional or local objectives. For both $N$ and $r_{\max }$, we sampled from the full uncertainty distributions, allowing the decision makers to express their risk tolerance in the choice of allowable take from its uncertainty distribution. In their present form, the median estimates of allowable take (Table 1) represent the upper end of what would be considered responsible take limits, unless there is an acceptable and defensible objective to reduce the current population in the eastern United States below half the carrying capacity. Previously, Runge et al. (2009) used the 20th quantile $(66,660)$ of the 2006 population estimate $(91,190)$ for Virginia to estimate an allowable take of 3,533 for that state. Using this lower quantile rather than the median reduces the risk of potentially exceeding take given uncertainty in data used to calculate take. The 20th quantile of the population estimate for Virginia in our updated analysis is approximately 84,092 vultures, which increased allowable take to 5,718 , an approximate $62 \%$ increase in allowable take between 2006 and 2015. If we used the median population size estimate of 117,741 from 2015, allowable take would increase to 7,798 , which represents an approximately $36 \%$ increase in take compared to the 20th quantile. The management objective and population size chosen by the decision maker will depend on whether their goals are to maintain or decrease the vulture populations, and whether the decision maker is risk neutral, risk averse, or risk seeking in achieving these goals. Runge et al. (2009) provide useful suggestions about determining management goals based on percent of carrying capacity, ratio of annual take compared to maximum sustained yield, or annual take as a percent of annual population.

\section{Biological Considerations for Black Vulture Take}

Runge et al. (2009) noted that the estimated allowable take rate was sensitive to age at first breeding, adult survival, and subadult survival. With respect to age at first breeding, within the orders of terrestrial predatory birds there is a general tendency for females to begin breeding earlier than males (Newton 1979), which can have demographic consequences (Millsap 2018) relevant to accurate estimation of sustainable harvest rates depending on which sex is used in estimating parameters of $r_{\max }$. Because we have no updated demographic data, our assessment does nothing to reduce this uncertainty, and gaining better data for these parameters is still an important need. Estimation of population size using the BBS data required conversion factors (e.g., percent of birds flying during surveys, detection rates of flying birds along BBS routes) that were based on sparse data. Runge et al. (2009) observed that better information concerning 

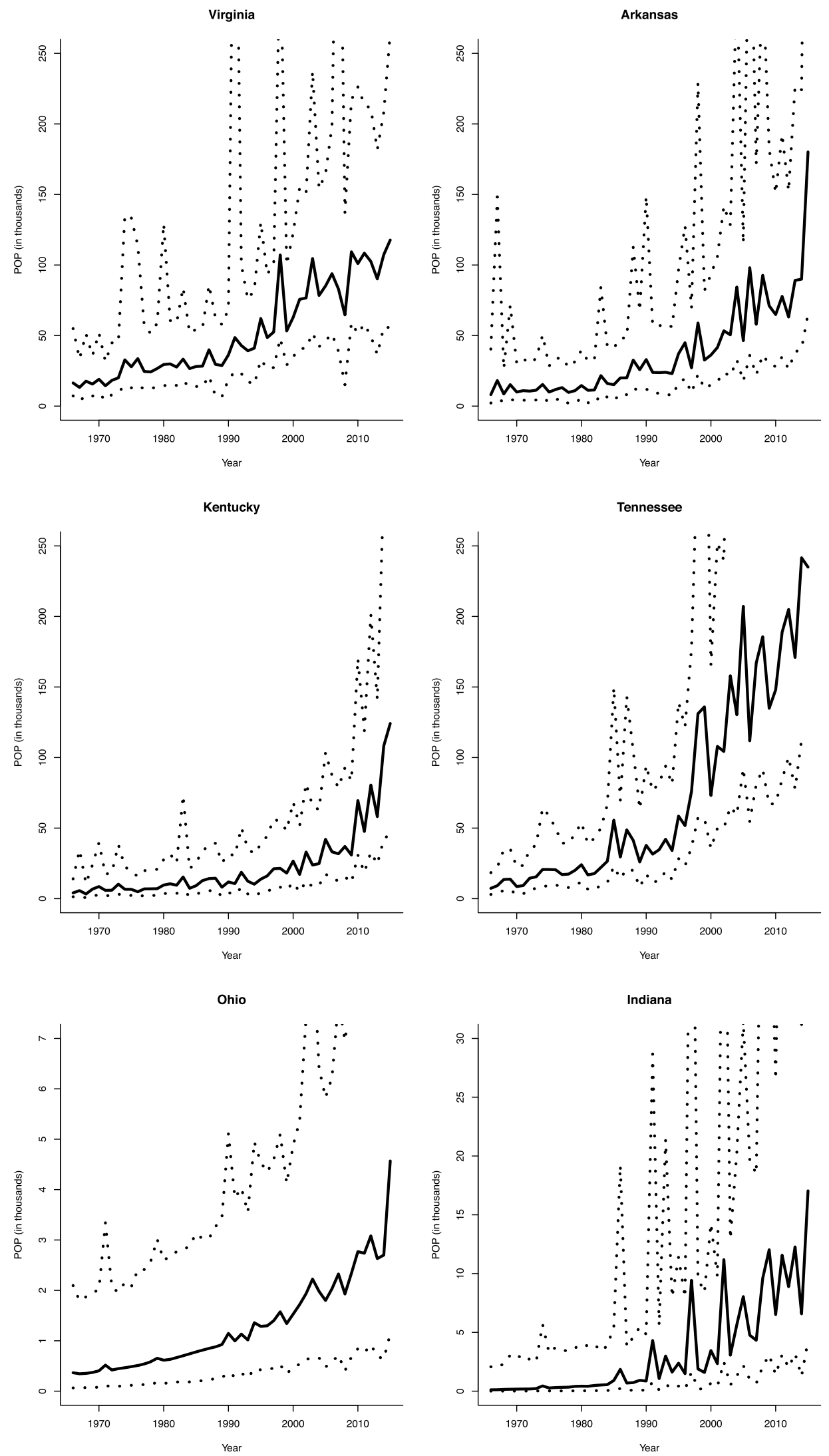

Figure 2. Population size estimates (POP) of black vultures for 6 eastern states in the United States based on Breeding Bird Survey data, 1966-2015. Dotted lines represent $95 \%$ credible intervals for population size estimates. We set $y$-axis limits to focus on clarity of presenting median trajectories rather than the full range of uncertainty. The scales of plots differ because of large differences in population estimates among the states. 

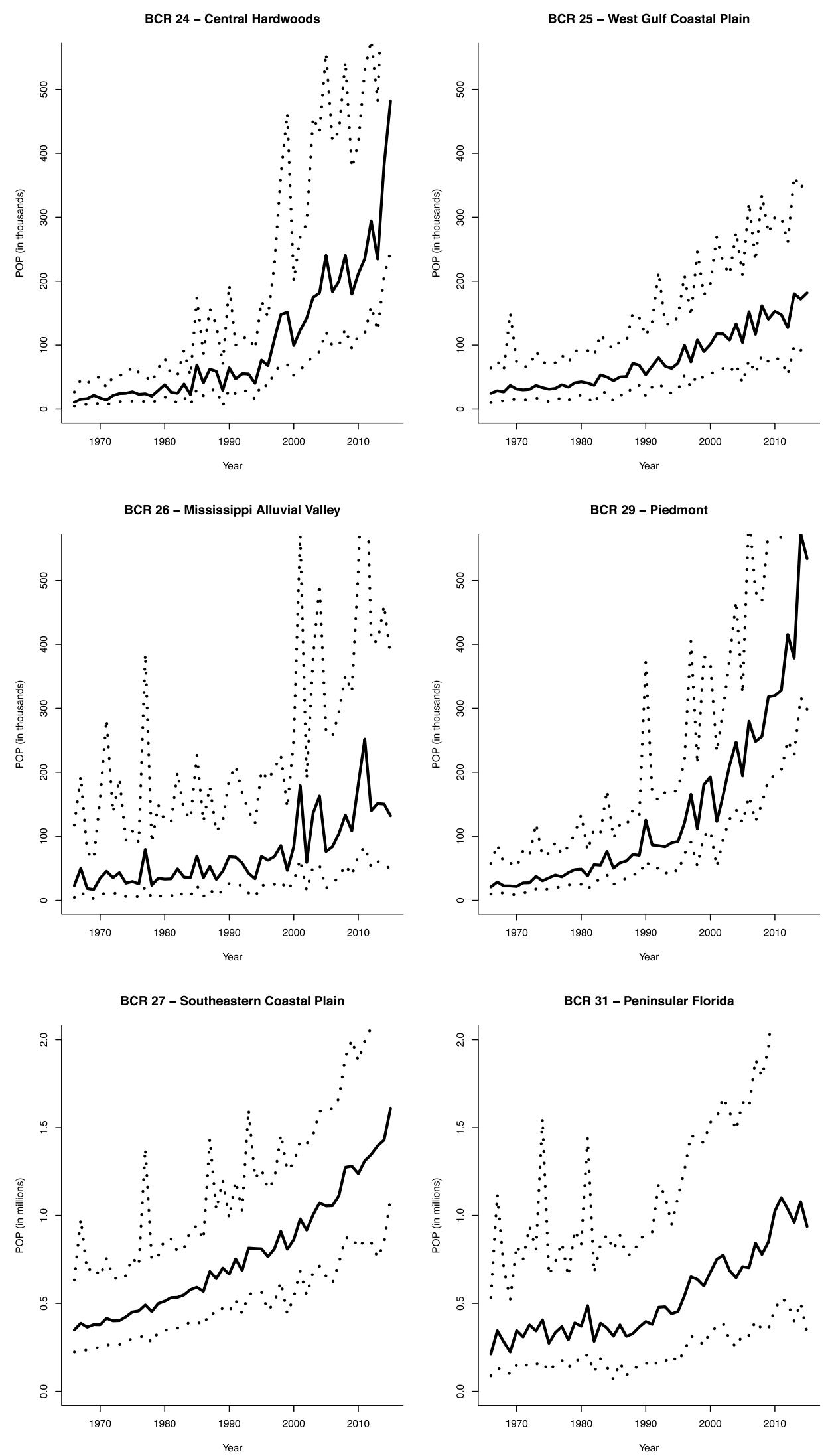

Figure 3. Population size estimates (POP) of black vultures for 6 Bird Conservation Regions (BCRs) in the eastern United States, 1966-2015. Dotted lines represent $95 \%$ credible intervals for population size estimates. We set $y$-axis limits to focus on clarity of presenting median trajectories rather than the full range of uncertainty. The scales of plots differ because of large differences in population estimates among the BCRs. 

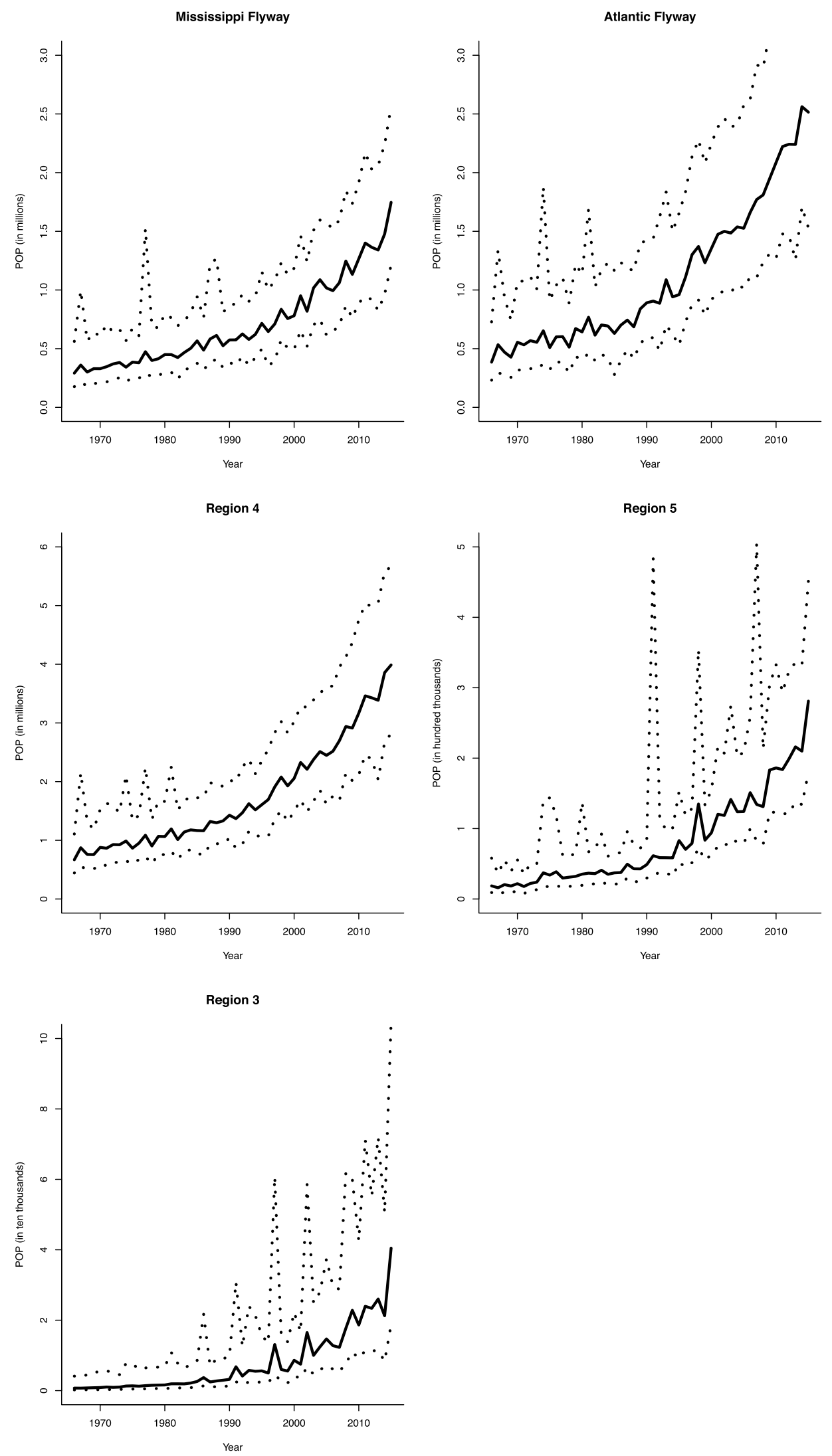

Figure 4. Population size estimates (POP) of black vultures for flyways and United States Fish and Wildlife Service (USFWS) regions in the eastern United States, 1966-2015. Dotted lines represent 95\% credible intervals for population size estimates. We set $y$-axis limits to focus on clarity of presenting median trajectories rather than the full range of uncertainty. The scales of plots differ because of large differences in population estimates among the flyways and USFWS regions. 
Table 1. Estimated median and $95 \%$ confidence intervals for the 2015 population size and allowable take for black vultures at different spatial scales and regions in the eastern United States.

\begin{tabular}{|c|c|c|c|c|c|}
\hline Scale $^{\mathrm{a}}$ & Region & Population estimate & 95\% CI population estimate & Allowable take ${ }^{b}$ & 95\% CI allowable take \\
\hline State & $\mathrm{AL}$ & 223,904 & $120,392-454,087$ & 14,954 & $2,078-45,284$ \\
\hline State & $\mathrm{AR}$ & 180,146 & $65,538-594,960$ & 11,588 & $1,326-52,116$ \\
\hline State & $\mathrm{DE}$ & 5,291 & $1,672-17,343$ & 335 & $38-1,547$ \\
\hline State & FL & $1,149,817$ & $494,534-2,505,744$ & 74,848 & $10,069-244,604$ \\
\hline State & GA & 707,042 & $382,588-1,365,728$ & 47,083 & $6,590-135,359$ \\
\hline State & IL & 5,851 & $1,574-19,224$ & 367 & $40-1,783$ \\
\hline State & IN & 17,039 & $4,299-78,110$ & 1,080 & $102-6,519$ \\
\hline State & KY & 124,159 & $46,187-320,164$ & 8,030 & $1,027-30,064$ \\
\hline State & LA & 433,436 & $223,757-905,473$ & 28,908 & $3,957-88,037$ \\
\hline State & $\mathrm{MD}$ & 71,423 & $38,008-143,186$ & 4,730 & $661-14,149$ \\
\hline State & $\mathrm{MO}$ & 6,970 & $1,618-37,158$ & 450 & $39-3,032$ \\
\hline State & MS & 381,332 & $168,646-908,494$ & 25,117 & $3,258-86,585$ \\
\hline State & $\mathrm{NC}$ & 126,976 & $47,447-277,815$ & 8,041 & $1,067-27,138$ \\
\hline State & $\mathrm{NJ}$ & 29,652 & $10,675-87,158$ & 1,915 & $230-7,918$ \\
\hline State & $\mathrm{OH}$ & 4,569 & $1,141-20,199$ & 295 & $28-1,666$ \\
\hline State & $\mathrm{PA}$ & 13,509 & $5,570-35,314$ & 877 & $110-3,249$ \\
\hline State & $\mathrm{SC}$ & 168,522 & $74,025-382,639$ & 11,038 & $1,450-37,310$ \\
\hline State & $\mathrm{TN}$ & 234,947 & $113,303-531,838$ & 15,487 & $2,094-51,045$ \\
\hline State & VA & 117,741 & $55,600-264,594$ & 7,798 & $1,047-25,396$ \\
\hline State & WV & 24,484 & $6,613-84,775$ & 1,530 & $165-7,469$ \\
\hline $\mathrm{BCR}$ & 24 & 482,062 & $245,871-998,141$ & 32,049 & $4,430-97,115$ \\
\hline $\mathrm{BCR}$ & 25 & 181,749 & $97,058-363,237$ & 12,013 & $1,673-36,399$ \\
\hline $\mathrm{BCR}$ & 26 & 132,126 & $47,911-381,133$ & 8,577 & $1,031-33,843$ \\
\hline $\mathrm{BCR}$ & 27 & $1,609,840$ & $1,104,298-2,447,916$ & 109,318 & $16,025-272,235$ \\
\hline $\mathrm{BCR}$ & 28 & 178,650 & $102,329-333,678$ & 12,012 & $1,707-34,347$ \\
\hline $\mathrm{BCR}$ & 29 & 533,958 & $298,346-998,673$ & 35,838 & $5,079-102,477$ \\
\hline $\mathrm{BCR}$ & 30 & 61,884 & $32,240-128,867$ & 4,126 & $570-12,549$ \\
\hline $\mathrm{BCR}$ & 31 & 937,075 & $334,493-2,309,294$ & 60,358 & $7,686-217,271$ \\
\hline $\mathrm{BCR}$ & 37 & 3,795 & $1,077-13,354$ & 240 & 25-1,192 \\
\hline Region & 3 & 40,477 & $18,815-104,851$ & 2,680 & $336-9,871$ \\
\hline Region & 4 & $3,987,747$ & $2,816,562-5,663,307$ & 268,422 & $39,849-647,943$ \\
\hline Region & 5 & 281,017 & $179,435-451,816$ & 18,948 & $2,730-48,643$ \\
\hline Flyway & Atlantic & $2,514,987$ & $1,529,781-4,098,188$ & 168,590 & $24,559-439,065$ \\
\hline Flyway & Mississippi & $1,746,922$ & $1,214,435-2,564,138$ & 118,179 & $17,444-289,585$ \\
\hline
\end{tabular}

${ }^{\mathrm{a}} \mathrm{BCR}=$ Bird Conservation Regions and Region $=$ United States Fish and Wildlife Service administrative regions.

${ }^{\mathrm{b}}$ Allowable take estimated by multiplying population size by maximum allowable take rate $\left(h_{\max }\right.$, median $\left.=0.068,95 \% \mathrm{CI}=0.01-0.15\right)$, which was estimated from a maximum intrinsic growth rate $\left(r_{\max }\right.$, median $\left.=0.105,95 \% \mathrm{CI}=0.02-0.19\right)$, a non-linear density dependence parameter $(\theta$, median $=2.56,95 \%$ $\mathrm{CI}=0.37-17.44)$, and a management objective of maximum sustained yield.

these factors would improve confidence in the population size estimates. We acquired additional data on the proportion of black vultures in flight during the BBS from 5 birds in telemetry studies at Kennedy Space Center (Avery 2017a) and Everglades National Park (Avery 2017b), Florida, USA. These new data (4.1\% and $4.5 \%$, respectively) are consistent with the estimate used by Runge et al. (2009; 4.17\%) thus bolstering confidence in this aspect of the population size estimation procedure.

Ecological theory and empirical research indicate that nonlinear density dependence is likely for many species of wildlife (Fowler 1981, Sæther et al. 2002), and researchers have reported that the form of density dependence can influence management (Johnson et al. 2012, Williams 2013). We accounted for the potential of non-linear density dependence in black vultures by using the theta-logistic model as the basis for our assessment. Estimating the nonlinear parameter $(\theta)$ is difficult with field data (Clark et al. 2010), so we used the equations developed by Johnson et al. (2012) to express the uncertainty in $\theta$. Regardless of the uncertainty associated with $\theta$, the coefficient of variation for the maximum allowable harvest rate increased by only approximately $7 \%\left(\mathrm{CV} \quad h_{\max }=43 \%\right.$ with $\theta=1$, and $\mathrm{CV}$ $h_{\max }=51 \%$ with the range of $\theta$ used in our assessment). Accounting for the possibility of non-linear density dependence provides a more realistic measure of uncertainty for our allowable take estimates.

\section{Spatial Allocation of Allowable Take}

The USFWS's Migratory Bird Program has a legal mandate and trust responsibility to conserve migratory bird populations for the enjoyment of the public in the United States (Runge et al. 2009). Enjoyment entails a variety of activities including consumptive (e.g., hunting) and non-consumptive (e.g., bird watching) uses. Therefore, the allocation of take permits for nuisance wildlife should balance the mandate and responsibilities of conserving populations while reducing human-wildlife conflicts. A critical consideration when attempting to strike a balance between conservation and reducing conflicts is the scale at which permits are allocated. For example, if we estimate an allowable number of take permits for the entire eastern United States population of black vultures, should those permits be allocated among states or regions within the black vulture range in proportion 
to the respective population sizes, or can large numbers of take permits be granted to local areas where nuisance complaints are particularly high? Allocating proportionally among states and regions at a large scale may impede the reduction of conflicts for some areas, whereas allocating to local regions may reduce species' populations to a level that does not meet trust responsibilities (i.e., if all permits are given to a particular area, local extirpations might result). We suggest there are 4 considerations relevant to the allocation of allowable take across space: the biological characteristics of the population, the legal standards for conservation implied in the relevant statutes, administrative efficiency, and other objectives expressed by stakeholders.

Biological characteristics.-From the biological perspective, species range, migration patterns, and the structure of genetic diversity across its range could be considered in how take is allocated. The underlying issue here is how we define the black vulture population (i.e., subpopulations or 1 overall population). Marking studies documenting overlap in ranges of birds among trapping sites from Florida to Virginia (Fig. S1, available online in Supporting Information; M. P. Milleson, U.S. Department of Agriculture Animal and Plant Health Inspection Service Wildlife Services [USDA/APHIS/WS], unpublished data), and an earlier study (Parmalee and Parmalee 1967) showed that some birds marked in Louisiana ended up in Florida and South Carolina. These data suggest that individuals in the southeastern United States interact throughout their range. In addition, genetic samples of birds trapped in south Florida indicate a strongly outbred population with no genetic structure (A.J. Piaggio, USDA/APHIS/WS, unpublished data). Therefore, movement and genetic data on black vultures do not provide a justification for managing take at scales less than a single United States population.

Legal standards. - The Migratory Bird Treaty Act does not provide specific legal requirements regarding the geographic or spatial scale for the management of take for migratory birds. The Migratory Bird Treaty Act specifically states that migratory birds can be legally taken "... from time to time, having due regard to the zones of temperature and to the distribution, abundance, economic value, breeding habits, and times and lines of migratory flight of such birds..." (16 USC \$704). The preferred alternative in the Eagle Rule Revision (USFWS 2016) is consistent with this mandate by managing take at the scale of flyways because eagles show migratory patterns that are consistent with the spatial arrangement of current flyway boundaries. In contrast, black vultures do not show movement patterns consistent with flyways or any other spatial scale on a regular basis. The Eagle Rule Revision also prohibits the extirpation of local populations, but that is not based on a legal interpretation from the Migratory Bird Treaty Act or the Bald and Golden Eagle Protection Act; this scale of management was incorporated in response to comments received from states and tribes during the public comment process associated with that rulemaking (USFWS 2016). Therefore, although there is no legal requirement regarding the spatial allocation of take for black vultures, future management objectives may require managing take at a finer scale.

Administrative efficiency.-The USFWS divided the United States into Headquarters and 8 administrative regions (https://www.fws.gov/where/, accessed 21 Jun 2018) to facilitate partnerships with local states, nongovernmental organizations, and other entities. Currently, migratory bird take permits are allocated through the regional offices of the USFWS, but managers do not consider how those permits are allocated within these regions. Similarly, the USFWS has identified administrative flyways based on general migratory routes between wintering and nesting areas. This system is commonly used for regulating harvest of waterfowl and some raptors (e.g., peregrine falcons [Falco peregrinus; USFWS 2017], bald [Haliaeetus leucocephalus] and golden eagles [Aquila chrysaetos; USFWS 2016]), and provides larger-scale administrative regions compared to the USFWS regions.

Stakeholder objectives.-Wildlife managers responsible for permitting take of black vultures need to consider local human values because permitting extensive take in 1 smallscale area could lead to complete local removal of the species from an area, which may or may not be acceptable to local residents. People within communities value wildlife differently based on recreation (e.g., hunting, wildlife viewing), economic (e.g., gain in revenue from hunters and birdwatchers, or loss due to damage), and cultural services. Competing values associated with wildlife may become contentious regardless of biological, legal, or administrative factors, so stakeholder input from local communities is an important consideration for take at local scales.

Resolving the question of the desired spatial scale for managing allowable take will involve consideration of these legal, administrative, and other policy elements, which is more appropriate for an evaluation under the National Environmental Policy Act than for this paper. Our results, however, provide guidance on how allowable take could be allocated, depending on the desired spatial scale of management.

\section{MANAGEMENT IMPLICATIONS}

The best available information suggests that at most, approximately 287,000 black vultures can be removed annually without adversely affecting the long-term viability of the black vulture population in the eastern United States. The actual level of authorized take is ultimately dependent upon management objectives. Even if such a level of lethal take is logistically feasible, there is no assurance that this management approach will measurably decrease the effect of black vultures on livestock or reduce the concerns of livestock producers throughout the black vulture's range. Other largescale applications of lethal control to manage avian depredations in agriculture have proved futile and ineffective (Linz et al. 2015). Targeted removal of selected individuals, those preying on livestock, as 1 component of a larger integrated management program, may be the most effective application of lethal control. Managers and stakeholders wishing to incorporate our take assessment into policy need 
to clearly articulate objectives, risk tolerance, and the spatial scale at which black vulture permits will be allocated. Once these considerations are clarified, our assessment could be updated to more accurately identify allowable take for black vultures in the eastern United States.

\section{ACKNOWLEDGMENTS}

L. M. Barnhill, T. R. Cooper, C. P. Dwyer, E. L. Kershner, and P. C. Toschik helped organize a workshop that motivated this work and provided valuable suggestions for the assessment. G. S. Boomer, M. J. Johnson, R. A. Long, R. P. White, and 2 anonymous reviewers provided editorial suggestions that greatly improved the manuscript. M. C. Sadlowski provided data on take permits for black vultures. The USFWS Region 8 Refuge Inventory and Monitoring, and Science Applications programs provided administrative support for GSZ. The findings and conclusions in this article are those of the authors and do not necessarily represent the views of the U.S. Fish and Wildlife Service.

\section{LITERATURE CITED}

Avery, M. L. 2004. Trends in North American vulture populations. Proceedings of the Vertebrate Pest Conference 21:116-121.

Avery, M. L. 2017a. Movements of black vultures trapped at the Kennedy Space Center. Final Study Report. National Wildlife Research Center, Fort Collins, Colorado, USA.

Avery, M. L. 2017b. Vulture movements and activity at Everglades National Park and Key West Naval Air Station. Final Study Report. National Wildlife Research Center, Fort Collins, Colorado, USA.

Avery, M. L., and J. L. Cummings. 2004. Livestock depredations by black vultures and golden eagles. Sheep and Goat Research Journal 19:58-63.

Avery, M. L., J. S. Humphrey, T. S. Daughtery, J. W. Fischer, M. P. Milleson, E. A. Tillman, W. E. Bruce, and W. D. Walter. 2011. Vulture flight behavior and implications for aircraft safety. Journal of Wildlife Management 75:1581-1587.

Avery, M. L., and M. Lowney. 2016. Vultures. Wildlife Damage Management Technical Series. USDA, APHIS, WS National Wildlife Research Center. Fort Collins, Colorado, USA.

Buckley, N. J. 1999. Black vulture (Coragyps atratus). Account 411 in A. F. Poole and F. B. Gill, editors. The birds of North America. Cornell Lab of Ornithology, Ithaca, New York, USA.

Caughley G. 1977. Analysis of vertebrate populations. John Wiley and Sons, New York, New York, USA.

Clark, F., B. W. Brook, S. Delean, H. R. Akçakaya, and C. J. A. Bradshaw. 2010. The theta-logistic is unreliable for modelling most census data. Methods in Ecology and Evolution 1:253-262.

Fowler, C. W. 1981. Density dependence as related to life history strategy. Ecology 62:602-610.

Gilpin, M. E., and F. J. Ayala. 1973. Global models of growth and competition. Proceedings of the National Academy of Science 70:3590-3593.

Humphrey, J. S., E. A. Tillman, and M. L. Avery. 2004. Vulture-cattle interactions at a central Florida ranch. Proceedings of the Vertebrate Pest Conference 21:122-125.

Johnson, F. A., M. A. H. Walters, and G. S. Boomer. 2012. Allowable levels of take for the trade in Nearctic songbirds. Ecological Applications 22:1114-1130.

Linz, G. M., E. H. Bucher, S. B. Canavelli, E. Rodriguez, and M. L. Avery. 2015. Limitations of population suppression for protecting crops from bird depredation: a review. Crop Protection 76:46-52.

Lowney, M. S. 1999. Damage by black and turkey vultures in Virginia, 1990-1996. Wildlife Society Bulletin 27:715-719.

Milleson, M. P., S. A. Shwiff, and M. L. Avery. 2006. Vulture-cattle interactions - a survey of Florida ranchers. Proceedings of the Vertebrate Pest Conference 22:231-238.
Millsap, B. A. 2018. Demography and metapopulation dynamics of an urban Cooper's hawk subpopulation. Condor 120:63-80.

Newton, I. 1979. Population ecology of raptors. Buteo Books, Vermillion, South Dakota, USA.

Ogada, D. L., F. Keesing, and M. Z. Virani. 2012. Dropping dead: causes and consequences of vulture population declines worldwide. Annals of the New York Academy of Sciences 1249:57-71.

Parmalee, P. W., and B. G. Parmalee. 1967. Results of banding studies of the black vulture in eastern North America. Condor 69:146-155.

Robbins, C. S., D. Bystrak, and P. H. Geissler. 1986. The Breeding Bird Survey: its first fifteen years, 1965-1979. U.S. Fish and Wildlife Service Resource Publication 157, Washington, D.C., USA.

Runge, M. C., W. L. Kendall, and J. D. Nichols. 2004. Exploitation. Pages 303-328 in W. J. Sutherland, I. Newton, and R. E. Green, editors. Bird ecology and conservation: a handbook of techniques. Oxford University Press, Oxford, United Kingdom.

Runge, M. C., and J. R. Sauer. 2017. Allowable take of red-winged blackbirds in the northern Great Plains. Pages 191-206 in G. M. Linz, M. L. Avery, and R. A. Dolbeer, editors. Ecology and management of blackbirds (Icteridae) in North America. CRC Press, Boca Raton, Florida, USA.

Runge, M. C., J. R. Sauer, M. L. Avery, B. F. Blackwell, and M. D. Koneff. 2009. Assessing allowable take of migratory birds. Journal of Wildlife Management 73:556-565.

Sæther, B.-E., and S. Engen. 2002. Pattern of variation in avian population growth rates. Philosophical Transactions of the Royal Society of London B. 357:1185-1195.

Sæther, B.-E., S. Engen, and E. Matthysen. 2002. Demographic characteristics and population dynamical patterns of solitary birds. Science 295:2070-2073

Sauer J. R., W. A. Link, J. E. Fallon, K. L. Pardieck, and D. J. Ziolkowski Jr. 2013. The North American Breeding Bird Survey 1966-2011: summary analysis and species accounts. North American Fauna 79:1-32.

Sauer, J. R., D. K. Niven, J. E. Hines, D. J. Ziolkowski Jr, K. L. Pardieck, J. E. Fallon, and W. A. Link. 2017. The North American Breeding Bird Survey, results and analysis 1966-2015. Version 2.07.2017. U.S. Geological Survey Patuxent Wildlife Research Center, Laurel, Maryland, USA.

Sibly, R. M., D. Barker, M. C. Denham, J. Hone, and M. Pagel. 2005. On the regulation of populations of mammals, birds, fish, and insects. Science 309:607-610.

Sibly, R. M., and J. Hone. 2003. Population growth rate and its determinants: an overview. Pages 11-40 in R. M. Sibly, J. Hone, and T. H. Clutton-Brock, editors. Wildlife population growth rates. Cambridge University Press, Cambridge, United Kingdom.

Slade, N. A., R. Gomulkiewicz, and H. M. Alexander. 1998. Alternatives to Robinson and Redford's method of assessing overharvest from incomplete demographic data. Conservation Biology 12:148-155.

U.S. Fish and Wildlife Service [USFWS]. 2016. Programmatic Environmental Impact Statement for the Eagle Rule Revision. USFWS, Washington, D.C., USA. https://www.fws.gov/migratorybirds/pdf/ management/FINAL-PEIS-Permits-to-Incidentally-Take-Eagles.pdf. Accessed 30 Oct 2018.

U.S. Fish and Wildlife Service [USFWS]. 2017. Migratory birds; take of peregrine falcons for use in falconry. Federal Register 82:42700-42701.

Williams, C. K. 2013. Accounting for wildlife life-history strategies when modeling stochastic density-dependent populations: a review. Journal of Wildlife Management 77:4-11.

Associate Editor: Ryan Long.

\section{SUPPORTING INFORMATION}

Additional supporting information may be found in the online version of this article at the publisher's website. 